unsatisfactory and this has been due in large measure to the use of a machine that has not proved reliable.

Dr. Blech has made extensive quotations from other peoples' work, especially that of Harvey Cushing, and he has attempted to describe the surgical technique much in the same way as one would find it in an ordinary text-book. This, we think, is a mistake, as the technique described in the space available can only be rather sketchy and is really outside the confines of his subject. As an example-the treatment of trigeminal neuralgia may be quoted, in which he describes the operation either on the ganglion itself or on the branches. Most surgeons in performing this operation would now attack the root.

A chapter is devoted to the effects of radium and, as a summary of radio-therapy, is to be commended. We are surprised that in talking of anxsthesia, ether is administered apparently frequently. We should have thought that this was a very dangerous practice when dealing with electrical currents such as are described here.

The illustrations are good, the book is well printed and can be commended to anyone who wishes to familiarise himself with the technique.

\section{FORENSIC MEDICINE :}

\section{A text-book for Students and a Guide for Practitioners.}

By Douglas J. A. KerR, M.D., F.R.C.P.E., D.P.H. 3rd Edition. A. \& C. Black, Ltd. London. 1939. Price 15s. Od.

This is an excellent book, written in direct precise English, so that the reader is left in no manner of doubt as to procedure and practice. The illustrations are numerous and of high quality.

In regard to more modern developments, the accounts of carbon monoxide poisoning, and of alcoholic poisoning in relation to the driving of motor cars, are very informative and helpful.

It is refreshing to read a book where the author has definite opinions as to the value of the various tests, pleas, theories, etc., which infest the subject of forensic medicine, and so aptly illumines many of them by cases from his own experience, and from current statistics, cases, and experimental work. The book is highly commended for students and for all manner of practitioners of medicine.

\section{CONGENITAL HEART DISEASE.}

By James W. Brown. John Bale Medical Publications Ltd. 1939. Pp. 271. Price 21s. Od.

This valuable addition to cardiological literature is the work of a physician who has amplified his own experience, gained as a medical officer to school clinics, by a wise and comprehensive study of the literature. Eight years attendance in five clinics produced more than three hundred and fifty cases of congenital heart disease in children, and these are the basis of the volume.
Lucidity of style is a great asset in Doctor Brown's description of a subject which, by its nature, requires much careful explanation of developmental abnormalities. The plan of the book is sensible and logical. There is no excessive verbosity, but no attempt is made to condense explanation to an extent which might cause obscurity.

The embryology of the subject is carefully defined in a special chapter, but the developmental theme is skilfully incorporated in the individual clinical types as they are dealt with in turn. The diagrams descriptive of the developmental changes are clear; the electrocardiograms, orthodiagrams and radiograms are adequate to the text throughout the book.

There is little to criticise in this excellent volume which provides a clear and concise but full description of the subject.

There are, however, a few minor points which might receive attention in a future edition. No mention is made of the lowered diastolic blood pressure which is common in cases of patent ductus arteriosus when the lesion is considerable, although the excessive arterial pulsation which accompanies it is referred to. In a few places where the clinical signs of right ventricular hypertrophy are mentioned the value of palpation of the hypertrophied and heaving chamber in the epigastric notch is omitted. In the case of congenital heart block with syncopal attacks, the value of ephedrine by mouth as a prophylactic measure is worthy of inclusion.

These are minor criticisms and should in no way deter the cardiologist, general physician or practitioner who desires to add to his library a full and useful book of reference on the subject.

\section{SEX AND INTERNAL SECRETIONS.}

\section{(Second Edition.)}

Edited by Edgar Allen. Pp. xxxvi, 1,346 and illustrated. Ballière, Tindall \& Cox, London. Price 54s. Od.

This is the second edition-the first being in 1932 - of the work done by the Committee for Research in Problems of Sex, sponsored by the United States National Research Council. It consists of papers by 27 investigators in the various branches of the subject under the capable editorship of Prof. Edgar Allen of Yale University, and each paper is a full and authoritative statement of the present knowledge in that particular branch backed by a wide survey of the bibliography. Illustrations and microphotographs-some in colour-are plentiful but not redundant, the print is comfortable to read and the book easy to find one's way about in.

It is, of course, primarily for the research worker, who will find it indispensable both in subject matter and in references, but it will also have a very wide appeal to all interested in the subject. There is a fascinating chapter on Sex Modification and Development, and another on 
the physiology of eggs and spermatozoa, and we practitioners will find much in the chapters on the vitamins, mammary gland and endocrines to clarify our ideas of the intricate inter-relationships of the various factors. Here we have a detailed and up-to-date survey of the whole subject in one volume and we owe a great debt to Prof. Allen and his co-workers for achieving this for us in so masterly a manner.

\section{THE BRITISH}

\section{ENCYCLOP EDIA OF MEDICAL}

\section{PRACTICE. Vol. XII. (TETANUS TO YELLOW FEVER.)}

Edited by SIR HuMpHry ROLIESTON BT. Butterworth \& Co. 1939. Price 35s. Od.

This, the final volume of this most excellent Encyclopædia of Medicine, is specially interesting not only because it completes the series but also because of its intrinsic value. It would almost seem as if fate had ordained its publication at this particular moment, since it appears just on the outbreak of war and deals with several subjects of peculiar military interest. Among these we would mention tetanus, trench fever, veldt sore, the typhus fevers and undulant fever, all of which have been, and which mayhap will be again scourges of our armies in the field. These conditions have been allotted to such well-known authorities as Dr. Knott, Major-General Sir John Megaw, Dr. Craib, and Lieut.-General Sir W. P. MacArthur. But these titles do not exhaust the list of even topical subjects considered in the volume. For instance, of interest both in peace and in war, is the subject of industrial poisoning which is dealt with at length by Dr. Donald Hunter. Poisoning in general is discussed by Dr. Roche Lynch.

Of more perennial interest there are full discussions of the deformities and diseases of the uterus by the late Sir Robert Thurstone, Sir Beckwith Whitehouse and Drs. Arthur Gemmell and W. Fletcher Shaw; vitamins by Dr. Leslie Harris; examination of the urine by Dr. T. Douglas Robertson; uræmia by Dr. Izod Bennett; and tuberculosis by Drs. Gloyne, Morland and Clifford Hoyle.

The publishers make a most important announcement in this volume. They state that,

"Although this is the last volume of the Encyclopædia, it is to be followed by annual supplements designed to keep the whole work up to date.

The first supplement, consisting of two volumes, is in active preparation and will be published shortly. Volume 1 will contain new information which has been suggested in many cases by the original contributors, and will be arranged on the well-known Butterworth keyed supplementary system, which facilitlates rapid reference from the original contributions to the new material. Volume II will contain, firstly, a series of critical surveys on the present position and possible developments of various branches of medicine, surgery, and the specialties, and secondly, abstracts from the world's medical literature covering the whole field of medicine."

This information should be particularly gratifying to all who have already subscribed for the work and should also be an inducement to those who do not possess it to subscribe even at this late date, for such a plan will ensure that the work will not readily become out of date. Indeed, if the supplements maintain the high standard of the original volumes, the work will be the ready book of reference throughout the whole field of medicine during their whole professional life.

\section{CFSARIAN SECTION : LOWER SEGMENT OPERATION.}

By C.McIntosh Marshall, F.R.C.S., Hon. Asst.

Surgeon, Liverpool Maternity Hospital, etc. Pp. 223 and illustrated. John Wright \& Sons Ltd. Bristol. Price 21s. Od.

This book is a most welcome addition to the obstetrician's library. It is a complete and careful survey of the operation from every standpoint, and from it the author has developed a technique which in his hands has given remarkable results.

After an anatomical and historical introduction to the subject, a clear and detailed description of the operation is given, the text being made still more lucid by a large number of excellent illustrations. Anæsthesia has a chapter to itself, and it is good to see the advantages of local anæsthesia stressed, although the claims of others are fairly discussed. The chapter on Dangers and Mishaps is typical of the critical manner in which the author is prepared to discuss every advantage and disadvantage of the operation, and though an enthusiast himself, he is not blind to the dangers even of the lower segment operation. The book is founded on a series of 246 cases, with no maternal and only five per cent. fœtal mortality, which certainly speaks for itself. It is a book by an obstetrician for obstetricians.

\section{STERILITY AND IMPAIRED FERTILITY.}

By CEDRIC LANe-Roberts, M.S., F.R.C.S., F.R.C.O.G., A I B E R T SHARMAN, M.D., M.R.C.O.G., KENNETH WALKER, F.R.C.S., and B. P. Wiesner, D.Sc., Ph.D., F.R.S.E. Pp. 412 and illustrated. Hamish Hamilton, Ltd., London. Price 14s. Od.

The problem of the infertile marriage is one of increasing importance in view of the modern tendency to limit families for economic and other reasons in healthy fertile people. Even 